\title{
Front Matter: Volume 8401
}

, "Front Matter: Volume 8401," Proc. SPIE 8401, Independent Component Analyses, Compressive Sampling, Wavelets, Neural Net, Biosystems, and Nanoengineering X, 840101 (20 June 2012); doi: 10.1117/12.977655

Event: SPIE Defense, Security, and Sensing, 2012, Baltimore, Maryland, SPIE. United States 


\section{PROCEEDINGS OF SPIE}

\section{Independent Component Analyses, Compressive Sampling, Wavelets, Neural Net, Biosystems, and Nanoengineering $X$}

Harold Szu

Liyi Dai

Editors

25-27 April 2012

Baltimore, Maryland, United States

Sponsored and Published by

SPIE 
The papers included in this volume were part of the technical conference cited on the cover and title page. Papers were selected and subject to review by the editors and conference program committee. Some conference presentations may not be available for publication. The papers published in these proceedings reflect the work and thoughts of the authors and are published herein as submitted. The publisher is not responsible for the validity of the information or for any outcomes resulting from reliance thereon.

Please use the following format to cite material from this book:

Author(s), "Title of Paper," in Independent Component Analyses, Compressive Sampling, Wavelets, Neural Net, Biosystems, and Nanoengineering X, edited by Harold SzU, Liyi Dai, Proceedings of SPIE Vol. 8401 (SPIE, Bellingham, WA, 2012) Article CID Number.

ISSN 0277-786X

ISBN 9780819490797

Published by

SPIE

P.O. Box 10, Bellingham, Washington 98227-0010 USA

Telephone +1 3606763290 (Pacific Time) · Fax +1 3606471445

SPIE.org

Copyright (C) 2012, Society of Photo-Optical Instrumentation Engineers

Copying of material in this book for internal or personal use, or for the internal or personal use of specific clients, beyond the fair use provisions granted by the U.S. Copyright Law is authorized by SPIE subject to payment of copying fees. The Transactional Reporting Service base fee for this volume is $\$ 18.00$ per article (or portion thereof), which should be paid directly to the Copyright Clearance Center (CCC), 222 Rosewood Drive, Danvers, MA 01923. Payment may also be made electronically through CCC Online at copyright.com. Other copying for republication, resale, advertising or promotion, or any form of systematic or multiple reproduction of any material in this book is prohibited except with permission in writing from the publisher. The CCC fee code is 0277-786X/12/\$18.00.

Printed in the United States of America.

Publication of record for individual papers is online in the SPIE Digital Library.

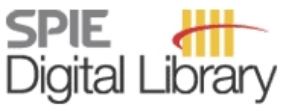

SPIEDigitalLibrary.org

Paper Numbering: Proceedings of SPIE follow an e-First publication model, with papers published first online and then in print and on CD-ROM. Papers are published as they are submitted and meet publication criteria. A unique, consistent, permanent citation identifier (CID) number is assigned to each article at the time of the first publication. Utilization of CIDs allows articles to be fully citable as soon as they are published online, and connects the same identifier to all online, print, and electronic versions of the publication. SPIE uses a six-digit CID article numbering system in which:

- The first four digits correspond to the SPIE volume number.

- The last two digits indicate publication order within the volume using a Base 36 numbering system employing both numerals and letters. These two-number sets start with 00, 01, 02, 03, 04, $05,06,07,08,09,0 A, 0 B \ldots 0 Z$, followed by 10-1Z, 20-2Z, etc.

The CID number appears on each page of the manuscript. The complete citation is used on the first page, and an abbreviated version on subsequent pages. Numbers in the index correspond to the last two digits of the six-digit CID number. 


\section{Contents}

vii Conference Committee
xi Introduction

WAVELET PIONEER AWARD

$840102 \quad$ MRA-based wavelet frames and applications: image segmentation and surface reconstruction (Invited Paper) [8401-01]

B. Dong, Univ. of Arizona (United States); Z. Shen, National Univ. of Singapore (Singapore)

\section{WAVELETS IMAGE APPLICATIONS I}

840103 Interdisciplinary education approach to the human science [8401-02]

H. Szu, The Catholic Univ. of America (United States); Y. Zheng, Alcorn State Univ. (United States); N. Zhang, Univ. of the District of Columbia (United States)

840104 Semi-supervised learning of heterogeneous data in remote sensing imagery [8401-03] J. Benedetto, W. Czaja, J. Dobrosotskaya, T. Doster, K. Duke, Univ. of Maryland, College Park (United States); D. Gillis, U.S. Naval Research Lab. (United States)

840105 A wavelet-based method for multispectral face recognition [8401-04]

Y. Zheng, Alcorn State Univ. (United States); C. Zhang, Z. Zhou, Univ. of Southern Mississippi (United States)

\section{MULTIPLE RESOLUTION ANALYSES}

840106 Face recognition from a moving platform via sparse representation [8401-05]

M. K. Hsu, The George Washington Univ. (United States); C. Hsu, The George Washington Univ. (United States) and Trident Systems Inc. (United States); T. N. Lee, The George Washington Univ. (United States); H. SzU, The George Washington Univ. (United States) and The Catholic Univ. of America (United States)

840107 Assessing the accuracy of image tracking algorithms on visible and thermal imagery using a deep restricted Boltzmann machine [8401-06]

S. Won, S. S. Young, U.S. Army Research Lab. (United States)

$840108 \quad$ PCA/LDA approach for text-independent speaker recognition [8401-07]

Z. Ge, S. R. Sharma, M. J. T. Smith, Purdue Univ. (United States)

\section{ICA UNSUPERVISED LEARNING PIONEER AWARD}

840109 Advances in audio source seperation and multisource audio content retrieval (Invited Paper) [8401-09]

E. Vincent, INRIA, Ctr. de Rennes - Bretagne Atlantique (France) 
$84010 G \quad$ Artificial neural network does better spatiotemporal compressive sampling [8401-17] S.-Y. Lee, KAIST (Korea, Republic of); C. Hsu, H. Szu, The Catholic Univ. of America (United States)

$8401 \mathrm{OH} \quad$ Video image cliff notes [8401-18]

H. Szu, The Catholic Univ. of America (United States); C. Hsu, Trident Systems Inc. (United States)

8401 ol Elucidating compressive sensing from Nyquist critical sampling [8401-19]

H. Szu, The Catholic Univ. of America (United States); C. Hsu, Trident Systems Inc. (United States); C. Nguyen, The Catholic Univ. of America (United States)

8401 0J Hyperspectral pixel classification from coded-aperture compressive imaging [8401-20] A. Ramirez, G. R. Arce, Univ. of Delaware (United States); B. M. Sadler, U.S. Army Research Lab. (United States)

\section{COMPRESSIVE SENSING AND SAMPLING APPLICATIONS}

8401 OK Household wireless electroencephalogram hat [8401-21]

H. Szu, The Catholic Univ. of America (United States); C. Hsu, Trident Systems Inc. (United States); G. Moon, Hallym Univ. (Korea, Republic of); T. Yamakawa, Fuzzy Logic System Institute (Japan); B. Tran, The Catholic Univ. of America (United States)

8401 OL Smartphone home monitoring of ECG [8401-22]

H. Szu, The Catholic Univ. of America (United States); C. Hsu, Trident Systems Inc. (United States); G. Moon, Hallym Univ. (Korea, Republic of); J. Landa, BriarTek, Inc. (United States); H. Nakajima, OMRON Corp. (Japan); Y. Hata, Univ. of Hyogo (Japan)

$84010 M$ Compressive sampling approach to visual attention in image scene analysis [8401-23] A. Singh, M. A. Pratt, C.-H. H. Chu, Univ. of Lovisiana at Lafayette (United States)

$84010 \mathrm{~N} \quad$ Avoiding the inverse fractal problem for compressive sampling of $1 / \mathrm{f}$ data sets [8401-25] H. Jaenisch, Johns Hopkins Univ. (United States) and Licht Strahl Engineering INC (United States)

\section{NANOENGINEERING PIONEER AWARD}

$840100 \quad$ Toward practical SERS sensing (Invited Paper) [8401-26]

Y. Zhao, The Univ. of Georgia (United States)

\section{SEMICONDUCTOR APPLICATIONS}

8401 OP A NANO enhancement to Moore's law [8401-27]

J. Wu, Y.-L. Shen, The George Washington Univ. (United States); K. Reinhardt, Air Force Office of Scientific Research (United States); H. Szu, The Catholic Univ. of America (United States) 
$84010 Q$ Carbon nanostructures properties by terahertz time-domain spectroscopy analysis for nanoengineering applications [8401-28]

E. Dadrasnia, H. Lamela, Carlos III de Madrid Univ. (Spain)

8401 OR Optimization of high speed pipelining in FPGA-based FIR filter design using genetic algorithm [8401-29]

U. Meyer-Baese, G. Botella, D. E. T. Romero, Florida State Univ. (United States); M. Kumm, Univ. of Kassel (Germany)

8401 OT A computational approach for statistical learning and inference [8401-31]

X. Chen, Southern Univ. (United States)

$84010 U$ An objective evaluation metric for color image fusion [8401-32]

W. Dong, The Univ. of Texas-Pan American (United States); Y. Zheng, Alcorn State Univ. (United States)

\section{SYSTEM BIOLOGY IMAGING PROCESSING}

8401 OW Biomedical wellness monitoring system based upon molecular markers [8401-34]

W. Ingram, The Univ. of Georgia (United States)

ENGINEERING SYSTEMS AND APPLICATIONS

8401 OY Further development of artificial neural networks for spectral interference correction in optical emission spectrometry [8401-36]

Z. Li, S. Huang, V. Karanassios, Univ. of Waterloo (Canada)

$84010 Z$ Quantitative analysis of breast DCE-MR images based on ICA and an empirical model [8401-37]

S. Goebl, Ludwig-Maximilians-Univ. München (Germany); C. Plant, The Florida State Univ. (United States); M. Lobbes, Maastricht Univ. Medical Ctr. (Netherlands); A. Meyer-Bäse, The Florida State Univ. (United States)

840110 Automated analysis of single and joint kinetic and morphologic features for non-masses [8401-38]

S. Hoffmann, Saarland Univ. (Germany); J. Shutler, Plymouth Marine Lab. (United Kingdom); M. Lobbes, Maastricht Univ. (Netherlands); B. Burgeth, Saarland Univ. (Germany);

A. Meyer-Bäse, The Florida State Univ. (United States)

840111 Spatio-temporal feature extraction for differentiation of non-mass-enhancing lesions in breast MRI [8401-39]

D. Ngo, O. Zavala, Florida State Univ. (United States); J. Shutler, Plymouth Marine Lab. (United Kingdom); M. Lobbes, Maastricht Univ., Medical Ctr. (Netherlands); M. Lockwood,

A. Meyer-Bäse, Florida State Univ. (United States)

840112 Enhanced decision making through neuroscience [8401-40]

H. Szu, U.S. Army Night Vision \& Electronic Sensors Directorate (United States); T. Jung,

S. Makeig, Univ. of California, San Diego (United States) 
840113 Feature selection in bioinformatics (Invited Paper) [8401-41]

L. Wang, Nanyang Technological Univ. (Singapore)

BIOMEDICAL WELLNESS LEADERSHIP AWARD

840114 Biomedical wellness challenges and opportunities (Invited Paper) [8401-42]

J. F. Tangney, Office of Naval Research (United States)

HUMAN MEASUREMENT SCIENCES

840115 SAFE for PTSD: noncontact psychophysiological measure based on high-resolution thermal imaging to aid in PTSD diagnosis and assessment of treatment [8401-43]

B. O. Familoni, L. Ma, Kinex, Inc. (United States); J. A. Hutchinson, U.S. Army Night Vision \& Electronic Sensors Directorate (United States); C. A. Morgan III, Yale Univ. School of Medicine (United States); A. Rasmusson, VA Boston Healthcare System (United States);

B. L. O'Kane, U.S. Army Night Vision \& Electronic Sensors Directorate (United States)

840116 Under-dermal emulator of vascular identification [8401-44]

J. Landa, R. Blake, A. Rich, BriarTek, Inc. (United States); H. Szu, The Catholic Univ. of America (United States)

840117 Adaptive Region of Interest (ROI) detection and tracking for respiration measurement in thermal video [8401-45]

B. Kaur, U.S. Army U.S. Army Night Vision \& Electronic Sensors Directorate (United States);

J. K. Nelson, George Mason Univ. (United States); T. Williams, B. L. O'Kane, U.S. Army U.S. Army

Night Vision \& Electronic Sensors Directorate (United States)

840118 Trans-skull ultrasonic Doppler system aided by fuzzy logic [8401-46]

Y. Hata, Univ. of Hyogo (Japan) and Osaka Univ. (Japan); M. Nakamura, N. Yagi, Univ. of Hyogo (Japan); T. Ishikawa, Ishikawa Hospital (Japan)

840119 Human care system for heart-rate and human-movement trajectory in home and its application to detect mental disease [8401-47]

Y. Hata, Univ. of Hyogo (Japan) and Osaka Univ. (Japan); S. Kanazawa, Univ. of Hyogo (Japan); M. Endo, N. Tsuchiya, H. Nakajima, OMRON Corp. (Japan)

8401 1A Systems Health Care: daily measurement and lifestyle change [8401-48] H. Nakajima, N. Tsuchiya, OMRON Corp. (Japan); T. Shiga, Omron Healthcare Co., Ltd. (Japan); Y. Hata, Univ. of Hyogo (Japan)

8401 1B Fundamental matrix and planar homographies in stereo vision [8401-49] Q. He, Mississippi Valley State Univ. (United States); C.-H. H. Chu, Univ. of Louisiana at Lafayette (United States)

Author Index 


\title{
Conference Committee
}

\author{
Symposium Chair \\ Kevin P. Meiners, Office of the Secretary of Defense (United States) \\ Symposium Cochair \\ Kenneth R. Israel, Lockheed Martin Corporation (United States) \\ Conference Chair \\ Harold Szu, U.S. Army Night Vision \& Electronic Sensors Directorate \\ (United States) \\ Conference Cochair
}

Liyi Dai, U.S. Army Research Office (United States)

Program Committee

Shun-ichi Amari, RIKEN (Japan)

Richard G. Baraniuk, Rice University (United States)

John J. Benedetto, University of Maryland, College Park (United States)

Chee-Hung Henry Chu, University of Louisiana at Lafayette (United States)

Kai-Dee Chu, U.S. Dept. of Homeland Security (United States)

Ronald R. Coifman, Yale University (United States)

John Daugman, University of Cambridge (United Kingdom)

Ronald G. Driggers, U.S. Naval Research Laboratory (United States)

Jide Familoni, U.S. Army Night Vision \& Electronic Sensors Directorate (United States)

Fredric M. Ham, Florida Institute of Technology (United States)

Yutaka Hata, University of Hyogo (Japan)

Charles C. Hsu, Trident Systems Inc. (United States)

Tzyy-Ping Jung, University of California, San Diego (United States)

Keith A. Krapels, U.S. Army Night Vision \& Electronic Sensors Directorate (United States)

Horacio R. Lamela Rivera, Universidad Carlos III de Madrid (Spain)

Douglas A. Lauffenburger, Massachusetts Institute of Technology (United States)

Soo-Young Lee, KAIST (Korea, Republic of)

Anke D. Meyer Baese, The Florida State University (United States)

Uwe Meyer Baese, The Florida State University (United States) 
Francesco Carlo Morabito, Università Mediterranea di Reggio Calabria (Italy)

Hiroshi Nakajima, OMRON Corporation (Japan)

Charles $\mathbf{C}$. Nguyen, The Catholic University of America (United States)

Hyung-Min Park, Sogang University (Korea, Republic of)

Kitt C. Reinhardt, Air Force Office of Scientific Research (United States)

Metin Sitti, Carnegie Mellon University (United States)

Jan-Olov Stromberg, Royal Institute of Technology (Sweden)

Nadarajen A. Vydelingum, National Institutes of Health (United States) and National Cancer Institute (United States)

Olaf Wolkenhaver, Universität Rostock (Germany)

Donald C. Wunsch II, Missouri University of Science and Technology (United States)

Ning Xi, Michigan State University (United States)

Takeshi Yamakawa, Kyushu Institute of Technology (Japan)

Yufeng Zheng, Alcorn State University (United States)

\section{Session Chairs}

Wavelet Pioneer Award

John J. Benedetto, University of Maryland, College Park (United States)

Wavelets Image Applications I

Yufeng Zheng, Alcorn State University (United States)

John J. Benedetto, University of Maryland, College Park (United States)

Multiple Resolution Analyses

Zuowei Shen, National University of Singapore (Singapore)

John J. Benedetto, University of Maryland, College Park (United States)

ICA Unsupervised Learning Pioneer Award

Soo-Young Lee, KAIST (Korea, Republic of)

Computational Intelligence I

Emmanuel Vincent, IRISA / INRIA Rennes (France)

Soo-Young Lee, KAIST (Korea, Republic of)

Computational Intelligence II

Soo-Young Lee, KAIST (Korea, Republic of)

Kenneth A. Byrd, U.S. Army Night Vision \& Electronic Sensors Directorate (United States)

Compressive Sampling Pioneer Award

Liyi Dai, U.S. Army Research Office (United States) 
Compressive Sampling Applications

Harold H. Szu, U.S. Army Night Vision \& Electronic Sensors Directorate (United States)

Liyi Dai, U.S. Army Research Office (United States)

Compressive Sensing and Sampling Applications

Soo-Young Lee, KAIST (Korea, Republic of)

Liyi Dai, U.S. Army Research Office (United States)

Nanoengineering Pioneer Award

Xi Ning, Michigan State University (United States)

Harold H. Szu, U.S. Army Night Vision \& Electronic Sensors Directorate (United States)

Semiconductor Applications

Yiping Zhao, The University of Georgia (United States)

Horacio R. Lamela Rivera, Universidad Carlos III de Madrid (Spain)

Systems Biology Pioneer Award

Nadarajen A. Vydelingum, National Institutes of Health (United States)

Anke D. Meyer Baese, The Florida State University (United States)

System Biology Imaging Processing

Chee-Hung Henry Chu, University of Louisiana at Lafayette (United States)

Xiaowei Zhuang, Harvard University (United States)

Engineering Systems and Applications

Xiaowei Zhuang, Harvard University (United States)

Babajide O. Familoni, U.S. Army Night Vision \& Electronic Sensors

Directorate (United States)

Biomedical Wellness Pioneer Award

Soo-Young Lee, KAIST (Korea, Republic of)

Yutaka Hata, University of Hyogo (Japan)

Human Measurement Sciences

Chee-Hung Henry Chu, University of Louisiana at Lafayette (United States)

Yutaka Hata, University of Hyogo (Japan) 
Proc. of SPIE Vol. $8401840101-10$

Downloaded From: https://www.spiedigitallibrary.org/conference-proceedings-of-spie on 26 Apr 2023 Terms of Use: https://www.spiedigitallibrary.org/terms-of-use 


\section{Introduction}

The eleventh annual SPIE conference on Independent Component Analysis (ICA), Compressive Sampling, Wavelets, Neural Networks, Biosystems and Nanoengineering, continues our yearly tradition of contributing and communicating knowledge to one another. The SPIE Defense Security and Sensing (DSS) Symposium has provided our community with the proper venue to exchange information, provide education through short courses and networking through various hospitality events. Boasting over 500 exhibiting vendors and talks given by over 7000 scientists and engineers worldwide, the symposium is an immense gathering. Our conference however, is relatively small, but has a rapid dissemination of the timely work in the disciplines covered. New to the conference this year is Compressive Sampling and post conference publication. We appreciate the timely submissions of our authors and the patience of our readers.

Being co-chairs, we often face questions about our goals and focus for the future of the conference series. To state the question plainly, how has the conference endured, and how can it continue to endure and evolve in a changing scientific environment? The answer lies partly in the following secret: We have adapted a workable system tested by the Nobel Foundation for over half a century-passing the baton of honor... "The past award recipients shall determine the new awardees." The role SPIE and the co-chairs serve are to act as facilitators for the decision process. A major difference between the systems is a lack of recourse in supporting the awardees. Thus we have improvised a temporary win-win-win solution: in order to prepare the interdisciplinary audience, state of the art knowledge is disseminated by both past and present award recipients, who are encouraged to teach short courses at the meetings.

Driven by our desire to learn from nature, the SPIE conference on wavelets has evolved, and is now in its $18^{\text {th }}$ year with SPIE. When the conference started 18 years ago (1994 in Orlando) progress began slowly. Then, year after year, knowledge began growing, building, and changing. The evolution of knowledge has led to a strong foundation for the work this year. The use of wavelets has seen much progress from a biomedical standpoint, from the 2012 Wavelet Pioneer Award Recipient Prof. Zuowei Shen (National University of Singapore), we have learned how to apply wavelet frames to image restoration, image segmentation and surface reconstruction. Unsupervised learning uses artificial neural networks to imitate the human brain's ability to learn from sensor pairs, a vector (not scalar) time series of data. The 2012 recipient of the Unsupervised Learning Neural Network Independent Component Analyses (ICA), Dr. Emmanuel Vincent (IRISA / INRIA Rennes, France), explained how ICA can be used for audio source separation and multisource audio content retrieval. Compressive sampling is not 
a post-processing compression, e.g. wavelet JPEG 2000 standard. Assuming a sparse information content, $k$ degree of freedom, Emmanuel Candes of Caltech (now at Stanford), Justin Romberg of GIT, Terrence Tao of UCLA and currently by David Donoho of Stanford (CRT\&D) took a pseudo-orthogonal set of $m$ linear mixtures, $m \sim 1.3 \mathrm{k}$, of the original sensed data X. CRT\&D applied an efficient linear programming to recover the original pixel data in LMS sense at the a priori constraint of sparseness, e.g. min. $|X|$. The 2012 Pioneer Award in Compressive Sampling was presented to Prof. Richard Baraniuk (Rice University) for demonstrated signal processing. We introduced our 2012 Nano-Engineering Pioneer Award recipient Prof. Yiping Zhao (University of Georgia), who will provide insight from the field of practical SERS sensing. He demonstrated that the aligned silver nanorod (AgNR) array substrates engineered by the oblique angle deposition method are capable of providing extremely high SERS enhancement factors $\left(>10^{8}\right)$. Today we are able to see and explore single-molecule activities using superresolution fluorescence microscopy that was invented by our 2012 System Biology Pioneer Award recipient, Prof. Xiaowei Zhuang (Harvard University). Finally, the powerful feature selection techniques are applied to the problems in bioinformatics by the Biomedical Wellness award recipient Prof. Lipo Wang (Nanyang Technological Univ., Singapore). The biomedical wellness challenges and opportunities are described by Dr. John F. Tangney (Office of Naval Research), the 2012 Leadership Award recipient in Biomedical Wellness. We wish to thank all of 2011 recipients, who headed the selection process for this year's awardees: Prof. John Benedetto, Prof. Metin Sitti, Dr. Hiroshi Nakajima, Prof. Doug Lauffenburger, Prof. Soo-Young Li and Dr. Hyung-Min Park. The conference would not be a success without you and your generous contributions.

We would also like to thank the SPIE technical support staff and last but certainly not least, we would like to thank the members of the program committee, especially the great effort led by our Web Master Yufeng Zheng, establishing a website collecting our accomplishment over the past 18 years.

Harold SzU Liyi Dai 